\title{
Editorial
}

\section{Mortalidad Infantil, indicador de calidad en salud}

María Luisa Ávila-Agüero

El cambio en las cifras de mortalidad infantil ha sido espectacular pero no milagroso. Es el producto de una serie de acciones dentro y fuera del sector salud, emprendidas por diferentes gobiernos y en diferentes épocas.

Los empeños de la humanidad por cuantificar el evento de la muerte, se remontan a la Inglaterra del siglo XVII. Graunt, en 1661, llama la atención sobre el hecho de que un tercio de todas las defunciones ocurrían en individuos menores de 5 años. Buchan en el siglo XVIII, observa que las defunciones infantiles representaban la mitad de las ocurridas en la población general. Villermé, en los inicios del siglo XIX, plantea que la tasa cruda de mortalidad general esta en estrecha relación con el ingreso promedio. Este concepto fue de aceptación en toda Francia, a mitad del siglo, donde establecen el claro vínculo entre el aumento de las tasas y los indicadores de pobreza y condiciones ambientales desfavorables.

En las postrimerías de XIX, el propio Villermé, reformula su planteamiento a la luz del análisis de nuevas consideraciones y la tasa de mortalidad infantil sustituye a la tasa cruda de mortalidad como indicador de salud y bienestar social. En 1880 se acepta de manera universal la definición de mortalidad infantil.

En el siglo siguiente Newsholme, posiciona el concepto de que la tasa de mortalidad infantil es el índice más sensible de salud comunitaria, eficiencia económica y bienestar social colectivo.

En nuestro medio el Dr. Carlos Durán Cartín, se preocupó por el tema y en 1924; apoya su posición con respecto a disminuir la mortalidad infantil en un análisis económico muy particular; él planteaba lo siguiente: "Si admitimos con los economistas que el valor de un hombre puede estimarse en 1500 colones, tendríamos cada año si pudiéramos salvar mil existencias, un beneficio de millón y medio de colones suma nada despreciable, sobre todo para aquellos que todo lo calculan en monedas de oro. Desde este punto de vista la protección de la niñez hasta hoy mirada con indiferencia por los Gobiernos resulta, no solo una obra altamente humanitaria, sino también una medida económica de primer orden". El Dr. Solón Nuñez Frutos, primer salubrista y primer Ministro de Salud de Costa Rica, continúa con la obra del Dr. Durán y le da un enorme impulso a la protección del binomio madre-niño, logrando con ello un eficiente control de enfermedades hasta entonces no tomadas en consideración. Aplicaron el axioma de Ellwood, relacionando la tasa de mortalidad infantil con el estado sanitario del país y reconociendo que un medio cultural más elevado propicia una disminución en dicha tasa.

Basados en estos conceptos, los progresos que se han efectuado en la lucha contra la mortalidad infantil en Costa Rica han sido enormes. La Tasa de la Mortalidad Infantil en el país, en el periodo comprendido entre 1990 al 2005 (Cuadro 1), ha descendido de 14,8 a 9,8 por mil. Desglosando dicha tasa de mortalidad según sus componentes se obtiene que la Mortalidad Neonatal descendió de una tasa de 8,8 a 7,1, para una reducción total de 1,7 puntos; dicha tasa representó el 72,6\% del total de defunciones en menores de un año en el último año, mientras que el componente postneonatal, en el mismo periodo, fue el componente que presentó el mayor descenso con 3,4 puntos y cuya tasa representó el $27,4 \%$ del total de muertes en menores de un año. 
Analizando las causas de la mortalidad infantil en nuestro medio, (Cuadro 2), encontramos que la principal causa de muerte corresponde a las afecciones originadas en el periodo perinatal, que concentran el $48 \%$ del total de defunciones de menores de un año en el 2005. En segundo lugar se registran las malformaciones congénitas con el $35 \%$, seguidas por las enfermedades respiratorias con el $7 \%$ y con un 3\% las enfermedades infecciosas y parasitarias. Este patrón se ha mantenido constante en los últimos años, con una tendencia a incrementarse la proporción de casos por malformaciones congénitas.

A nivel mundial las causas que provocan muertes durante el primer año de vida son diversas, relacionadas con problemas en el ambiente, en la infraestructura socioeconómica y sanitaria de la sociedad; con los aspectos biológicos individuales, de la salud en general y de la salud sexual y reproductiva en particular. Por ello nada o casi nada de lo que tiene que ver con la mortalidad infantil, escapa al desarrollo social, pues ni aún los aspectos atribuidos al sistema sanitario quedan fuera de este marco.

Por ser éste un grupo de edad vulnerable y por lo que implica la supervivencia durante este período, la mortalidad infantil traduce más que la calidad de atención a un sector de la población, traduce la calidad de un sistema sanitario. Es requisito indispensable de las tasas de mortalidad infantil bajas, que exista una plataforma sociocultural que le sirva de sustento, en la que las responsabilidades familiar, comunitaria y social juegan un papel preponderante.

El acceso a agua potable, vivienda digna, calzado, saneamiento ambiental en especial el manejo y disposición final de los residuos sólidos, alimentación adecuada $\mathrm{y}$ educación son premisas de la salud y de la reducción de la

\section{Cuadro 1. Tasas de Mortalidad Infantil, Neonatal y} Posneonatal, Contribución porcentual por componentes, Costa Rica 1990-2005, Tasas por mil n.v.

\begin{tabular}{|cccccc|}
\hline \multirow{2}{*}{ Año } & Infantil & \multicolumn{2}{c}{ Neonatal } & \multicolumn{2}{c|}{ Posneonatal } \\
& Tasa & Tasa & $\%$ & Tasa & $\%$ \\
\hline 1990 & 14,78 & 8,78 & 59,4 & 6,1 & 41,3 \\
1991 & 13,90 & 8,61 & 61,9 & 5,2 & 37,4 \\
1992 & 13,70 & 8,69 & 63,4 & 5,01 & 36,6 \\
1993 & 13,70 & 8,94 & 65,3 & 4,73 & 34,5 \\
1994 & 13,00 & 8,94 & 68,8 & 4,06 & 31,2 \\
1995 & 13,25 & 8,53 & 64,4 & 4,72 & 35,6 \\
1996 & 11,83 & 7,76 & 65,6 & 4,07 & 34,4 \\
1997 & 14,20 & 9,15 & 64,4 & 5,05 & 35,6 \\
1998 & 12,60 & 8,14 & 64,6 & 4,46 & 35,4 \\
1999 & 11,78 & 8,09 & 68,7 & 3,69 & 31,3 \\
2000 & 10,21 & 7,06 & 69,1 & 3,15 & 30,9 \\
2001 & 10,82 & 7,49 & 69,2 & 3,34 & 30,9 \\
2002 & 11,15 & 7,66 & 68,7 & 3,49 & 31,3 \\
2003 & 10,10 & 6,98 & 69,1 & 3,12 & 30,9 \\
2004 & 9,25 & 6,73 & 72,8 & 2,52 & 27,2 \\
2005 & 9,78 & 7,10 & 72,6 & 2,68 & 27,4 \\
\hline Fuente: INEC/DSS, Ministerio Salud. & & & \\
\hline
\end{tabular}

mortalidad infantil de manera sostenible. La accesibilidad a los servicios de salud, acceso con calidad, equidad y oportunidad, lo que tiene mucho que ver con el entorno socioeconómico ejerce una influencia indiscutible en el comportamiento del indicador.

Poder controlar con información y responsabilidad el número de hijos y el momento del embarazo, recibir atención prenatal calificada, favorecerse de la institucionalización del parto, de los programas de vacunación actualizados acorde a los patrones epidemiológicos nacionales y de la puericultura son derechos básicos de todos los seres humanos que deben ser garantizados por los gobiernos.

La atención del niño enfermo con recursos suficientes, puestos a su disposición con oportunidad constituye un pilar fundamental en el logro de la reducción de la mortalidad infantil.

Las transformaciones dentro del sistema sanitario, como en el resto de los sectores sociales tienen un denominador común y es el desarrollo socioeconómico y cultural de la nación, pero el énfasis está en la prioridad que la sociedad y el estado dan a la salud infantil. Lo cual es, también sin lugar a dudas, el resultado de una cultura impregnada de humanismo.

El desarrollo social y económico es fundamental para la consecución de la reducción de la tasa mortalidad infantil, pero no es suficiente, ya que la igualdad de oportunidades de supervivencia y la prioridad que los gobiernos otorguen a la salud infantil y de las madres gestantes, es un determinante significativo.

Las principales causas de mortalidad infantil en el mundo, no son las afecciones perinatales, sino, la pobreza, producto de la desigual repartición de la riqueza, el discriminado acceso a la paz, la nutrición, la educación y a los servicios básicos de salud. Por suerte en Costa Rica creemos en la paz, la educación y la salud. El reto presente y futuro es ser capaces de definir políticas claras y permanentes que sigan siendo orientadas hacia los grupos más vulnerables, que podamos bajo la estrategia de la promoción de la salud, convertir a la salud en una cultura de vida y apostar por trabajar sobre los determinantes sociales de la salud. Con ello lograremos continuar gozando de los altos índices de salud que nos han caracterizado.

Finalizo con un frase del poeta libánes Gibrân Jalîl "Protegedme de la sabiduría que no llora, de la filosofía que no ríe y de la grandeza que no se inclina ante los niños”. 


\begin{tabular}{|c|c|c|c|c|c|c|c|c|c|c|c|c|}
\hline \multirow[b]{2}{*}{ Grandes Causas } & \multicolumn{3}{|c|}{2002} & \multicolumn{3}{|c|}{2003} & \multicolumn{3}{|c|}{2004} & \multicolumn{3}{|c|}{2005} \\
\hline & $\mathrm{N}^{\circ}$ & $\%$ & Tasa & $\mathrm{N}^{\circ}$ & $\%$ & Tasa & $\mathrm{N}^{\circ}$ & $\%$ & Tasa & $\mathrm{N}^{\circ}$ & $\%$ & Tasa \\
\hline Causas perinatales & 401 & 50,6 & 5,6 & 365 & 48,2 & 4,9 & 330 & 49,4 & 4,6 & 339 & 48,4 & 4,7 \\
\hline Malformaciones congénitas & 235 & 29,6 & 3,3 & 240 & 32,5 & 3,3 & 205 & 30,7 & 2,8 & 242 & 34,6 & 3,4 \\
\hline Enf sistema respiratorio & 67 & 8,4 & 0,9 & 63 & 8,5 & 0,9 & 54 & 8,1 & 0,7 & 52 & 7,4 & 0,7 \\
\hline Enf infecciosas y parasitarias & 20 & 2,5 & 0,3 & 18 & 2,4 & 0,2 & 15 & 2,2 & 0,2 & 20 & 2,9 & 0,3 \\
\hline Causas externas & 15 & 1,9 & 0,2 & 15 & 2 & 0,2 & 14 & 2,1 & 0,2 & 16 & 2,3 & 0,2 \\
\hline Las demás causas & 55 & 6,9 & 0,8 & 46 & 6,2 & 0,7 & 50 & 7,5 & 0,7 & 31 & 4,4 & 0,4 \\
\hline
\end{tabular}

